\title{
Axis II comorbidities are less common in people with borderline personality disorder who are in remission
}

Zanarini MC, Frankenburg FR, Vujanovic AA, et al. Axis II comorbidity of borderline personality disorder: description of 6-year course and prediction to time-to-remission. Acta Psychiatr Scand 2004;1 10:416-20.

Does remission of severe borderline personality disorder affect the prevalence of axis II comorbidities?

\section{METHODS}

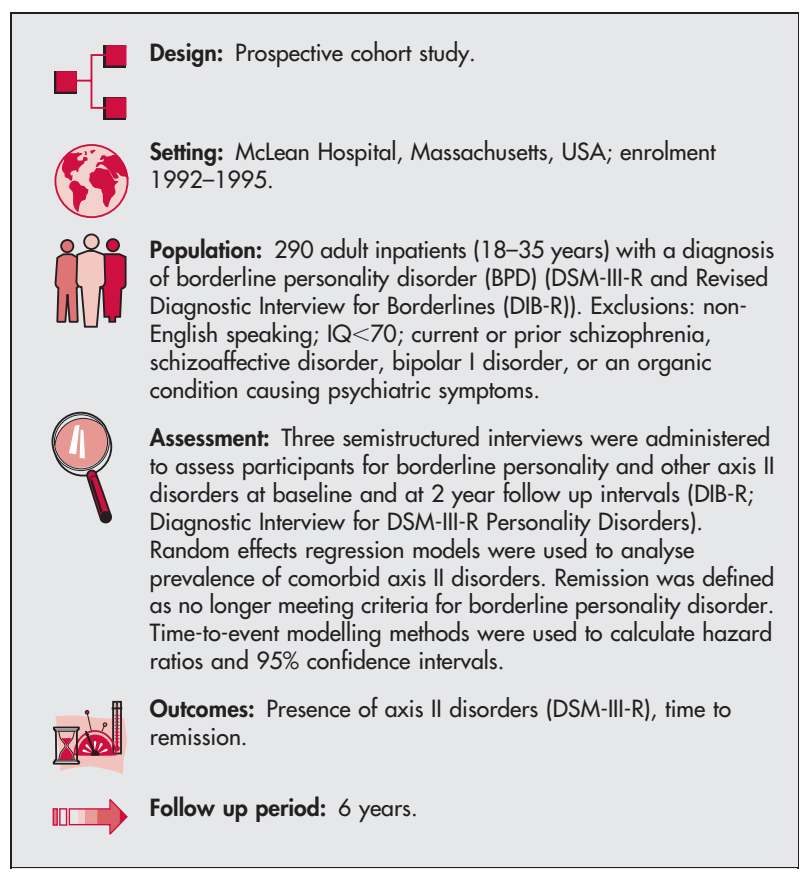

\section{MAIN RESULTS}

At 6 years, 202 people had experienced remission from severe BPD. The prevalence of dependent, avoidant, self-defeating, narcissistic, and histrionic personality disorders was significantly higher among people whose BPD had never remitted, compared with those who had experienced remission (see table, no significant difference in other

Table Axis II disorders that differed significantly between remitted and non-remitted borderline personality disorder (BPD) at baseline

\begin{tabular}{|c|c|c|c|c|}
\hline \multirow[b]{2}{*}{ Axis II disorder } & \multicolumn{2}{|c|}{ Never-remitted BPD } & \multicolumn{2}{|c|}{ Remitted BPD } \\
\hline & $\begin{array}{l}\text { Baseline } \\
n=88\end{array}$ & $\begin{array}{l}6 \text { years } \\
n=64\end{array}$ & $\begin{array}{l}\text { Baseline } \\
n=202\end{array}$ & $\begin{array}{l}6 \text { years } \\
n=200\end{array}$ \\
\hline Dependent & $56 \%$ & $45 \%$ & $42 \%$ & $8 \%$ \\
\hline Avoidant & $50 \%$ & $59 \%$ & $36 \%$ & $16 \%$ \\
\hline Self-defeating & $34 \%$ & $27 \%$ & $22 \%$ & $1 \%$ \\
\hline Narcissistic & $19 \%$ & $2 \%$ & $7 \%$ & $2 \%$ \\
\hline Histrionic & $16 \%$ & $6 \%$ & $8 \%$ & $2 \%$ \\
\hline
\end{tabular}

For correspondence: Dr Mary C Zanarini, McLean Hospital, 115 Mill Street, Belmont, MA 02478, USA; zanarini@mclean.harvard.edu

Sources of funding: National Institute of Mental Health, USA. axis II disorders). The overall prevalence of axis II comorbidities declined over time. However, avoidant personality disorder increased in the never-remitted group. People without avoidant, dependent, or self-defeating personality disorders had a significantly earlier remission from BPD than people with these comorbidities (selfdefeating: HR for remission 4.1, 95\% CI 1.8 to 9.3; avoidant: HR 2.0, 95\% CI 1.3 to 2.9 ; dependent: HR $3.5,95 \%$ CI 2.2 to 5.7 ).

\section{CONCLUSIONS}

In people with severe BPD the prevalence of axis II comorbidities decreases with time, particularly in people in remission. The presence of self-defeating, avoidant and dependent personality disorders increases time to remission in people with BPD, suggesting that these axis II disorders may hinder recovery.

\section{NOTES}

Axis II disorders were assessed using DSM-III-R criteria, which is likely to differ from DSM-IV classification of axis II disorders. As participants were recruited as very disturbed inpatients, the findings of this study may not apply to less severely disturbed people with BPD. The study did not clearly establish the temporal relationship between comorbidity and remission, therefore a causality cannot be imputed.

\section{Commentary}

raditionally, it has been thought that personality disorders remain stable over time. Although temporal stability is central to these diagnoses constructs, reviews of the available empirical data suggest that, overall, personality disorders demonstrate only moderate stability and they can improve at a slow pace. 'Previous studies with a follow up of 2 years had found that personality disorders can change in their severity or in their expression. ${ }^{2}$ The most important aspect of this prospective research is that it questions the irreversibility of borderline personality disorder (BPD). The major finding of this study is that BPD declines with time, although some of people with BPD will continue to have other axis II diagnoses. Comorbidity of avoidant, dependent and self-defeating personality disorders diminishes the probability of remission of BPD.

BPD is a complex and serious mental disorder that occurs in $1-2 \%$ of the general population. It is associated with serious impairment in psychosocial functioning. The results of the study have some important implications for clinical practice: (1) systematic evaluation of comorbid personality disorders seems relevant for prognosis; and (2) people with BPD should receive treatment over a long period of time. Such treatment should include psychotherapy and pharmacotherapy.

More prospective studies with long term follow up must be done to assess which are the best treatments for these patients.

Ana González-Pinto, PhD, MD Hospital Santiago, University of the Basque Country, Spain

1 Grilo CM, McGlashan TH. Stability and course of personality disorders. Curr Opin Psychiatry 1999;12:157-62.

2 Grilo CM, Sanislow CA, Gunderson JG, et al. Two-year stability and change of schizotypal, borderline, avoidant, and obsessive-compulsive personality disorders. J Consult Clin Psychol 2004;72:767-75.

3 Oldham JM, Bender DS, Skodol AE, et al. Testing an APA practice guideline: symptom-targeted medication utilization for patients with borderline personality disorder. J Psychiatr Pract 2004;10:156-61. 